\title{
CHIKUNGUNYA FEVER: ASSESSMENT OF KNOWLEDGE AMONGST PHYSICIANS OF LAHORE.
}

\footnotetext{
1. MBBS

Post Graduate Trainee Community Medicine

LMDC, Lahore.

2. MBBS

Post Graduate Trainee Community Medicine

LMDC, Lahore.

3. MBBS, MCPS, FCPS

Professor Community Medicine LMDC, Lahore.
}

Correspondence Address:

Dr. Saadia Ayub

Department of Community Medicine

LMDC, Lahore.

saadiaayub89@gmail.com

Article received on:

25/02/2020

Accepted for publication:

$16 / 05 / 2020$

\begin{abstract}
Saadia Ayub', Rafia Hussain², Seema Daud ${ }^{3}$
ABSTRACT... Objectives: The objective of this study was to assess the knowledge of doctors regarding chikungunya fever and their practices. Study Design: Cross Sectional study. Setting: Medicine OPDs of Ghurki Trust Teaching Hospital, Sheikh Zayed Hospital, and Sir Ganga Ram Hospital. Period: From January to March 2018. Material \& Methods: Sample of 121 carried out using a structured questionnaire. Sampling population were doctors working in medicine departments of the three hospitals. Questionnaire assessed knowledge of doctors and were scored accordingly and grouped into good, adequate and poor knowledge. Scores of doctors were then analyzed with different variables. Results: Mean score was $9.4 \pm 3.5$ with $45.5 \%$ having poor knowledge, $37.2 \%$ with adequate knowledge and only $17.4 \%$ with good knowledge. Applying test of significance showed the variables with significant difference in scoring were age of doctors, designation of doctors and whether a doctor was confident enough to treat a chikungunya patient. Conclusion: Knowledge regarding chikungunya was adequate however a significant number of doctors pointed out that their knowledge was insufficient and they felt under-confident treating a patient. Therefore, more education and awareness in the form of workshops, seminars and conferences are required on chikungunya.
\end{abstract}

Key words: Chikungunya, Knowledge, Physicians.

Article Citation: Ayub S, Hussain R, Daud S. Chikungunya Fever: Assessment of knowledge amongst physicians of Lahore. Professional Med J 2020; 27(10):22352240. DOI: $10.29309 / T P M J / 2020.27 .10 .4592$

\section{INTRODUCTION}

In the midst of the unwavering burden of infectious diseases, arthropod-borne viral diseases have emerged out as an important public health concern, primarily due to climate change, poor public awareness and adoption of inadequate preventive strategies. Chikungunya shares the same vector as dengue, Aedes ageypti, with more or less same clinical spectrum; the disease however, follows a less fatal clinical course. $^{1,2}$ The causative agent is alpha virus genus of the family Togaviridae. Chikungunya, derived from Kimakonde language, means 'to become contorted' referring to the crouched posture attained as a result of the debilitating polyarthralgias in chikungunya. Chikungunya is characterised by symptoms of fever and severe joint pain and may also include muscular aches, headache, nausea, fatigue and a morbilliform rash in $60-80 \%$ of the patients. ${ }^{2,3}$ Though the disease itself is self-limiting, the arthritic pains may last up to months or even years. ${ }^{4}$
Chikungunya originates from central Africa but the first major outbreak was reported in the 1960s in Bangkok. ${ }^{5}$ Chikungunya was discovered in Pakistan in rodents back in 1983 but it was not until November 2016 that Pakistan saw its first epidemic. ${ }^{6} \mathrm{~A}$ few cases of Chikungunya were also reported during the 2011 dengue epidemic. ${ }^{7}$ A deaf ear to $\mathrm{NIH}$ alerts after outbreaks in India and the unchecked cross-border mobility led to Chikungunya outbreak here in Pakistan in 2016. ${ }^{8}$ A study carried out in Karachi Pakistan in 2017 found 199 confirmed cases of chikungunya out of suspected 1275 patients. This study also highlighted the lack of knowledge regarding chikungunya amongst patients. ${ }^{9}$ It was seen that in tropical climates like those in South Asia, there is co-existence of dengue and chikungunya. This was documented by various studies conducted in Pakistan, India and Singapore. These studies compared clinical presentation of both diseases followed by confirmation of diagnosis of Chikungunya. ${ }^{9-12}$ 
In Pakistan, Dengue attained huge media-hype followed by tremendous public fright, and a golden chance for the government to attain political interests yielding huge allocation of funds and health sector resources for its prevention and control. Hence a disease so similar to dengue should be undoubtedly diagnosed in order to prevent over-enthusiastic management and treatment plans. In doing so many unreported cases of chikungunya would be identified and the unnecessary resources that are spent on dengue could be spent elsewhere. The objective of this study is to assess knowledge and practices of doctors regarding chikungunya fever in a private, a government and a trust hospital of Lahore, Pakistan.

\section{MATERIAL \& METHODS}

Our study is a cross-sectional study carried out at three different hospitals of Lahore namely Ghurki Trust teaching hospital (GTTH), Sheikh Zayed Hospital (SZH) and Sir Ganga Ram Hospital (SGRH) to assess knowledge and practices of treating Chikungunya fever patients. Data collection was carried out from January to March 2018. Sampling technique used was convenience sampling. Total sample size was 121 with a response rate of $71 \%$ from a total of 170 doctors in medicine departments of the 3 hospitals combined. Inclusion criteria for sample were all doctors working in medicine departments of GTTH, SZH and SGRH. Other health care workers and medical students were excluded from the study. Data collection was done using a structured questionnaire. The questionnaire consisted of two sections. Section one comprised of demographic profile of each doctor while section two assessed the knowledge of each doctor about chikungunya followed by their practices.

Data was collected after informed consent from each participant. Statistical software spss version 21 was used for data entry and analysis. Knowledge was assessed by adding up of correct answers. There were a total of 19 correct answers. Average score was calculated followed by categorization of scores in poor, adequate and good. Each questionnaire was scored on a scale of 0-19 with poor scoring from 0-8, adequate from
9-12 and good score from 13-19.

Scores were compared between different variables followed by application of non-parametric tests kruskal wallis and mann whitney $U$ to calculate P-value and to analyze its significance. Before commencement of the research approval was taken from the ethical review board of Lahore Medical and Dental College as well as from medical superintendents of the concerned hospitals.

\section{RESULTS}

The respondents had a mean age of $27.5 \pm 6.0$. Total respondents were 121 out of which $71 \%$ (86) were female. There were $23(19 \%)$ respondents from GTTH, 26 (21.5\%) from SZH and 72 (59.5\%) from SGRH. 81\% (98) held only an MBBS degree and 23 (19\%) also held an additional postgraduation qualification. 57 (47\%) were house officers and medical officers, while there were 56 (46\%) post-graduate trainees and $8(7 \%)$ were consultants. Overall the knowledge assessed showed that mean score was $9.4 \pm 3.5$ with 55 (45.5\%) having poor knowledge, 45 (37.2\%) with adequate knowledge and only 21 (17.4\%) with good knowledge regarding chikungunya.

Respondents were categorized into 20-25 years, 26-30 years and >30 years of age and their scores compared (as shown in Table-l) using Kruskal Wallis test which showed P-value of 0.002 indicating age had a very significant effect on chikungunya knowledge. With increasing age and thus experience, a doctor was more likely to have superior knowledge regarding chikungunya. Though, it seemed that doctors of Ganga Ram hospital had better scores but on applying Kruskal Wallis Test a P-value of 0.534 was obtained demonstrating that difference in scores of the three hospitals was insignificant. Kruskal Wallis test was again applied to see significance of difference in scores amongst doctors with different designation. Consultants ranked the highest followed by post-graduate trainees and house/ medical officers with similar results. A P-value of 0.001 was obtained depicting that difference in scores of different designations was significant. Therefore with higher designation 
there were higher scores. 88 (73\%) of doctors agreed that they were not confident about managing a patient with chikungunya. On comparing scores, higher scores were seen in those who said they were confident enough to treat patients with their current knowledge as opposed to the under confident doctors ( $p$-value $=0.03$ ). $107(88.4 \%)$ wished to receive more information about Chikungunya. Most doctors (41\%) said that their main source of information regarding chikungunya was the internet or electronic media as shown in Figure-1. 77\% (93) wished for more seminars, workshops and conferences in order to enhance their present knowledge regarding chikungunya.

The last portion of the questionnaire comprised of practices of doctors while treating patients of chikungunya. Only 16 doctors (13.2\%) said they encountered a chikungunya patient. Out of these 16 , only $8(50 \%)$ said they gave anti-pyretic and analgesics to the patients, and 9 (56\%) said they hospitalized the patients for observation. The scores of these doctors who encountered chikungunya patients are also shown in Table-l. Mann-Whitney $U$ test was applied which obtained a P-value of 0.556 signifying no difference of scoring between those who did and those who didn't encounter patients. Only $14 \%$ of the respondents said there was a standard isolation area in their hospital for dengue or chikungunya patients whereas $19.8 \%$ were not even aware if any isolation area was present in the hospital or not.

\section{Sources of information}

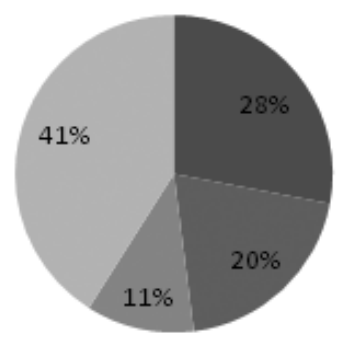

Figure-1. Source of current information regarding Chikungunya.

\section{DISCUSSION}

The eyes see what the mind knows. Early diagnosis and prompt treatment are the pivotal modes of secondary level of disease prevention. Early clinical diagnosis based on clinical signs and symptoms of the disease is inevitable in an economically friable country like Pakistan. The clinicians can make the correct clinical diagnosis only when the knowledge of the disease is comprehensive and the clinical practice regarding the treatment is flawless.

\begin{tabular}{|c|c|c|c|c|c|}
\hline \multirow{2}{*}{$\begin{array}{l}\text { Variable } \\
(\mathrm{N}=121)\end{array}$} & & \multicolumn{3}{|c|}{ Questionnaire Score } & \multirow{2}{*}{ P-Value } \\
\hline & & Poor & Adequate & Good & \\
\hline \multirow{2}{*}{ Age (years) } & $20-25(n=54)$ & 27 & 19 & 8 & \multirow{2}{*}{0.002} \\
\hline & $>30(n=14)$ & 2 & 4 & 8 & \\
\hline \multirow{2}{*}{ Hospital } & Ghurki Trust Hospital $(n=23)$ & 9 & 12 & 2 & \multirow{2}{*}{0.534} \\
\hline & Sir Ganga Ram Hospital $(n=72)$ & 31 & 26 & 15 & \\
\hline \multirow{3}{*}{ Designation } & PG Trainee $(n=56)$ & 27 & 22 & 7 & \multirow{3}{*}{0.001} \\
\hline & House/ Medical Officer $(n=57)$ & 28 & 21 & 8 & \\
\hline & Consultant $(n=8)$ & 0 & 2 & 6 & \\
\hline $\begin{array}{l}\text { Encountered chikungunya } \\
\text { patient? }\end{array}$ & No $(n=105)$ & 49 & 38 & 18 & 0.556 \\
\hline
\end{tabular}


In our study, the average knowledge score came out to be "adequate" (this outcome variable labelled as fair in similar studies), the results being consistent with another nationwide study. ${ }^{12}$ Based on the knowledge scores majority of the participants had poor knowledge, a considerable number had adequate/fair knowledge while only a small number had good knowledge. This discrepancy among the knowledge scores are contrary to the already conducted nationwide study among Health Care Workers ${ }^{12}$ where the majority had fair/adequate knowledge while those with poor and good knowledge were almost nearly of the same percentages. Another study conducted in Rawalpindi in 2017 also had results in contrast to ours where only a small percentage had poor/inadequate knowledge and a clear majority had good knowledge score. ${ }^{13}$

A large majority of the clinicians were aware that mosquito is the responsible vector for the spread of chikungunya, similar to previous studies ${ }^{12,13,14}$ however in contrast another study ${ }^{15}$ conducted in 2014 showed only a small percentage of participants knew about the vector. In our study $59.5 \%$ knew about the breeding sites of mosquito as opposed to $89 \%$ in an Indian study. ${ }^{16}$

Similarly, our study showed only a small majority (44.6\%) knew of the causative viral agent, contrary to another study, where an overwhelming majority (76.24\%) knew about the exact etiological agent. ${ }^{13}$ However, in a study conducted in 2015 in Karachi ${ }^{17}$ this particular knowledge was found to be as low as $22.2 \%$. The particular question was considered as more of the "bookish" content rather than of any clinical significance. The distinction of the exact viral agent is of utmost diagnostic significance serologically. Awareness of majority of clinicians regarding the specific diagnostic test PCR and ELISA was in contrast with the previous study $(43.7 \%) .{ }^{13}$

When inquired about the clinical course majority (78\%) were sure about the clinical symptoms of chikungunya which is very much comparable to the other studies $(64.5 \%$ and $65.5 \%)$ respectively ${ }^{12,13}$, while in a Columbian study $92 \%$ correctly identified the symptoms. ${ }^{18}$ Though, it is in contrast to another study conducted in Karachi where only $27.7 \%$ knew about the symptoms ${ }^{17}$ and in India where only $22 \%$ of the health care workers knew the symptoms. ${ }^{16}$

Alarmingly, only a small number (38\%) were aware of arthritis as a distinguishing clinical feature between chikungunya and dengue, and an even more marginal number (19\%) knew of the life-long immunity yielded by one time chikungunya infection. However, in contrast to a previous study ${ }^{12}$, majority knew that symptomatic management with fluid and electrolyte replacement along with anti-pyretics and antiinflammatory was the treatment of choice; these results were also similar to another study where $72 \%$ knew about the exact management. ${ }^{13}$

In our study $67 \%$ of the respondents knew that chikungunya had no currently available commercial vaccine, the results being consistent with a previous Indian study ${ }^{19}$ while in another local study only $34.5 \%$ of the health care workers knew about the non-availability of the vaccine. ${ }^{12}$

Like any other vector-borne disease, preventive measures form the most important mode of disease control in case of chikungunya. In our study $58 \%$ of the respondents knew about mosquito repellents and nets, while 56\% agreed upon drainage of stagnant water, while only $22 \%$ agreed upon the wearing of protective clothing as preventive measures against chikungunya which is in contrast to the previous studies results ${ }^{13,20}$ where a good majority knew about the exact preventive measures.

Though falsified in our study, there is a general public perception that there is disparity of knowledge among the clinicians belonging to different clinical settings viz a government hospital, a semi-government and a private/trust hospital which is in contrast to the previous studies. ${ }^{12,13}$ However there was a very strong positive association between designation and knowledge level, and also between age and knowledge level, portraying that there is plenty of room for learning among the young juniors and a lot for the seniors to impart. A significant 
majority admitted that they were less confident about managing a patient with chikungunya and wished to receive more knowledge about it. In fact, when scores of those who had encountered chikungunya patients were compared with those who had not, no significance was seen reiterating the doctors' lack of confidence.

Our study proved the scarcity in knowledge of doctors, especially young doctors concerning chikungunya. This evokes a dire need for the medical education departments of the medical colleges to lay stress on emerging diseases like chikungunya. All the previous studies agreed to the fact that chikungunya was not a topic that was dealt in medical colleges. Hence it is the responsibility of the medical education departments in collaboration of the public health and clinical departments to stay abreast with the emerging diseases, emphasizing on them in lectures and tutorials. Moreover on post graduate level, as rightly pointed out by our respondents, more seminars, workshops and conferences should be conducted while print and electronic media should go hand in hand to keep the clinicians abreast with the emerging disease threats and how to control them, primarily by prevention and then early diagnosis and treatment.

\section{CONCLUSION}

Our study established that knowledge regarding chikungunya aetiology as well as prevention and treatment were adequate amongst doctors of Ghurki Hospital, Sheikh Zayed Hospital and Ganga Ram Hospital. On the other hand, majority of the doctors felt their knowledge on the subject was insufficient making them under confident in treating a chikungunya patient. Most respondents pointed out the dire need for more seminars, workshops and conferences in order to enhance their current knowledge on the subject.

\section{Copyright $\Subset 16$ May, 2020.}

\section{REFERENCES}

1. World Health Organization. www.who.int. Fact sheets/ Details/ Chikungunya. $12^{\text {th }}$ April 2017.
2. Park K. Park's textbook of preventive and social medicine. 21st Edition. Jabalpur India: Banarsidas Bhanot Publishers; 2012.

3. Staples JE, Breiman RF, Powers AM. Chikungunya fever: an epidemiological review of a re-emerging infectious disease. Clinical infectious diseases. 2009 Sep 15;49(6):942-8. http://www.antimicrobe. org/h04c.files/history/CID-Staples-Chikungunya\%20 reemerging-2009.pdf.

4. Paul BJ, Pannarkady G, Moni SP, Thachil EJ. Clinical profile and long-term sequelae of Chikungunya fever. Indian Journal of Rheumatology. 2011 Mar 1;6(1):12-9. https://www.thelancet.com/pdfs/journals/ laninf/PIIS1473-3099(17)30074-9.pdf.

5. World Health Organization. Outbreak and spread of chikungunya. Wkly Epidemiol Rec 2007; 82:409-15.

6. Darwish MA, Hoogstraal H, Roberts TJ, Ahmed IP, Omar F. A sero-epidemiological survey for certain arboviruses (Togaviridae) in Pakistan. Transactions of the Royal Society of Tropical Medicine and Hygiene. 1983 Jan 1;77(4):442-5. https://www.ncbi. nlm.nih.gov/pubmed/6314612.

7. Afzal MF, Naqvi SQ, Sultan MA, Hanif A. Chikungunya fever among children presenting with nonspecific febrile illness during an epidemic of dengue fever in Lahore, Pakistan. Merit Res J Med Med Sci. 2015;3(3):69-73. https://pdfs.semanticscholar.org/84e0/ a0b28beff30f4a21b5e65891eec5d02c0b33.pdf.

8. Mallhi TH, Khan YH, Khan AH, Tanveer N, Qadir MI. First chikungunya outbreak in Pakistan: A trail of viral attacks. New microbes and new infections. 2017 Sep 1; 19:13-4. https://www.ncbi.nlm.nih.gov/pmc/articles/ PMC5480274/pdf/main.pdf.

9. Naqvi S, Bashir S, Rupareliya C, Shams A, Giyanwani PR, Ali Z, Qamar F, Kumar V, Talib V. Clinical spectrum of chikungunya in Pakistan. Cureus. 2017 Jul;9(7). Available from: https://www.ncbi.nlm.nih.gov/ pubmed/28924518.

10. Chahar HS, Bharaj P, Dar L, Guleria R, Kabra SK, Broor S. Co-infections with chikungunya virus and dengue virus in Delhi, India. Emerging infectious diseases. 2009 Jul;15(7):1077. https://www.ncbi.nlm.nih.gov/ pmc/articles/PMC2744227/pdf/08-0638_finalD.pdf.

11. Furuya-Kanamori L, Liang S, Milinovich G, Magalhaes RJ, Clements AC, Hu W, Brasil P, Frentiu FD, Dunning $R$, Yakob L. Co-distribution and co-infection of chikungunya and dengue viruses. BMC infectious diseases. 2016 Dec;16(1):1-1. https://rdcu.be/boiQF. 
12. Mallhi TH, Khan $\mathrm{YH}$, Tanveer $\mathrm{N}$, Bukhsh $\mathrm{A}$, Khan $\mathrm{AH}$, Aftab RA, Khan $\mathrm{OH}$, Khan TM. Awareness and knowledge of Chikungunya infection following its outbreak in Pakistan among health care students and professionals: a nationwide survey. PeerJ. 2018 Aug 30;6:e5481. https://peerj.com/articles/5481/.

13. Mansoor VB, Ahmed U, Jahanzaib M, Ali Z, Saeed $\mathrm{HA}$, Hassan F. An assessment of knowledge of Chikungunya fever among the postgraduate trainees, medical officers and private general practitioners of Islamabad, Rawalpindi and Wah. Annals of PIMS ISSN. 2017;1815:2287. https://apims.net/apims_old/Volumes/ Vol13-2/7-An\%20assessment\%20of\%20knowledge\%20 of $\% 20$ Chikungunya $\% 20$ fever\%20among $\% 20$ the $\% 20$ postgraduate\%20trainees\%20medical\%20officers\%20 and\%20private\%20general\%20practitioners.pdf.

14. Setbon M, RaudeJ, PottratzD. Chikungunya on Réunion Island: social, environmental and behavioural factors in an epidemic context. Population. 2008;63(3):491518. DOI: 10.3917/pope.803.0491.

15. Gul S, Aziz S, Tarik S. Chikungunya-the need for instigating awareness in Pakistan. International Journal of Pharmaceutical Research. 2014;12(3):2277-7873. http://www.academia.edu/7588488/Chikungunya_The Need_for_Instigating_Awareness_in_Pakistan

16. Thakor NC, Vikani SK, Nagar AA. Impact of educational intervention regarding mosquito-borne diseases and their control measures among multipurpose health workers (MPHWs) of Patan district, Gujarat, India. International Journal of Medical Science and Public Health. 2015 Nov 1;4(11):1620-4. https:// www.ejmanager.com/mnstemps/67/67-1430846194. pdf?t $=1551333107$
17. Weaver SC, Lecuit M. Chikungunya virus and the global spread of a mosquito-borne disease. New England Journal of Medicine. 2015 Mar 26;372(13):1231-9. http://pngpaediatricsociety.org/ wp-content/uploads/2015/12/Weaver-SC-Chikungunyavirus-global-spread-NEJM-2015.pdf-PDF-2.pdf

18. Bedoya-Arias JE, Murillo-García DR, Bolaños-Muñoz E, Hurtado-Hurtado N, Ramírez-Jaramillo V, GranadosÁlvarez S, Rodríguez-Morales AJ. Healthcare students and workers' knowledge about epidemiology and symptoms of chikungunya fever in two cities of Colombia. The Journal of Infection in developing countries. 2015 Mar 15;9(03):330-2. https://www.ncbi. nlm.nih.gov/pubmed/25771475.

19. Millman AJ, Esposito DH, Biggs HM, Decenteceo M, Klevos A, Hunsperger E, Munoz-Jordan J, Kosoy OI, McPherson H, Sullivan C, Voorhees D. Chikungunya and dengue virus infections among United States community service volunteers returning from the Dominican Republic, 2014. The American Journal of Tropical Medicine and Hygiene. 2016 Jun 1;94(6):133641. https://www.ncbi.nlm.nih.gov/pubmed/26976891.

20. Corrin T, Waddell L, Greig J, Young I, Hierlihy C, Mascarenhas M. Risk perceptions, attitudes, and knowledge of chikungunya among the public and health professionals: a systematic review. Tropical medicine and health. 2017 Dec 1;45(1):21. https://www. ncbi.nlm.nih.gov/pmc/articles/PMC5582396/.

\section{AUTHORSHIP AND CONTRIBUTION DECLARATION}

\begin{tabular}{|c|c|c|c|}
\hline Sr. \# & Author(s) Full Name & Contribution to the paper & Author(s) Signature \\
\hline 1 & Saadia Ayub & $\begin{array}{l}\text { Concept, Literature review, Designing } \\
\text { Questionnaire, Data collection, Data } \\
\text { entry. Data analvsis. Write up. }\end{array}$ & $\begin{array}{l}\text { spacia ayub } \\
\text { fy }\end{array}$ \\
\hline 2 & Rafia Hussain & $\begin{array}{l}\text { Concept, Literature review, Designing } \\
\text { QUestionnaire, Data collection, Data } \\
\text { entry. Write up. }\end{array}$ & $\begin{array}{l}\text { Rafa Hussain } \\
\text { Refia }\end{array}$ \\
\hline 3 & Seema Daud & $\begin{array}{l}\text { Concept, Designing Questionnaire, } \\
\text { Data analysis, Overall supervision. }\end{array}$ & Seema Daud \\
\hline
\end{tabular}

